\section{Mini Mouth Care Matters targets children's oral health on hospital wards}

The oral health of children in hospital is recognised as fundamental to their wellbeing thanks to the Mini Mouth Care Matters programme. The programme is benefitting thousands of children throughout the UK, thanks to the work of Dr Urshla (Oosh) Devalia, the national lead for Mini MCM (pictured).

A consultant in paediatric dentistry, Dr Devalia began devising Mini Mouth Care Matters (Mini MCM) nearly three years ago. At the heart of the programme is training for ward staff in hospitals to ensure that young in-patients always benefit from an oral health check. Hospital teams are taught to 'lift-thelip' so they have the confidence to look inside the mouth of young patients and understand any warning signs.

In addition to training, a range of resources, including an assessment tool, is made available to hospital-based healthcare practitioners. The programme branding includes a little elephant by the name of Elwood, a reminder to 'never forget' tooth brushing. Images of Elwood are now to be found in hospitals up and down the country beside the beds of paediatric patients, and also on posters and leaflets in hospital staff rooms and waiting areas.

The British Society of Paediatric Dentistry (BSPD) has applauded the programme. Spokesperson Claire Stevens said: 'It's incredible to see the way in which this programme is not only embedded as routine in hospitals with paediatric wards but also that it's extending into other settings including the training of health visitors and hospice staff.

'The small adaptations in care delivered by Mini MCM can significantly improve the quality of life of this cohort of children and young people and also provide new knowledge and skills for healthcare practitioners who learn to "lift the lip". As

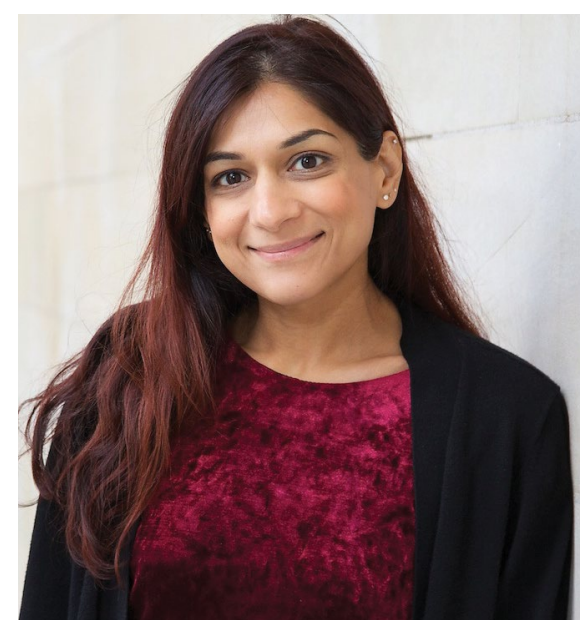

an innovative and transferable programme, Mini MCM has outstripped its vision.'

Mini MCM was modelled on the Mouth Care Matters programme devised and led by Mili Doshi to benefit older patients in residential and hospital settings by training their carers in mouth care.

The Mini MCM resources can be downloaded from: https://www. bspd.co.uk/Professionals/Resources/ mini-mouth-care-matters.

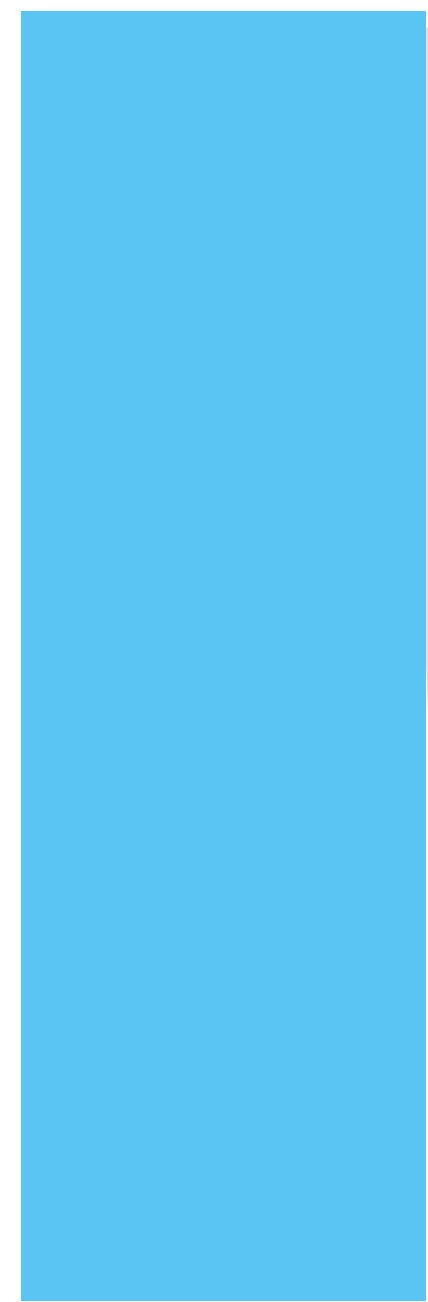

